DOI: 10.1515/ausfm-2018-0006

\title{
The Camera in House Arrest. Tactics of Non-Cinema in Jafar Panahi's Films
}

\author{
Judit Pieldner \\ Sapientia Hungarian University of Transylvania (Miercurea Ciuc, Romania) \\ E-mail: pieldnerjudit@uni.sapientia.ro
}

\begin{abstract}
In close intratextual connection with earlier pieces of Jafar Panahi's oeuvre, pre-eminently The Mirror (Ayneh, 1997) and Offside (2006), his recent films made in illegality, including This Is Not a Film (In film nist, Jafar Panahi and Mojtaba Mirtahmasb, 2011), Closed Curtain (Pardeh, Jafar Panahi and Kambuzia Partovi, 2013) and Taxi Tehran (Jafar Panahi, 2015), reformulate the relationship between cinema and the "real," defying the limitations of filmmaking in astounding ways. The paper addresses the issue of noncinema, pertaining to those instances of cinematic "impurity" in which "the medium disregards its own limits in order to politically interfere with the other arts and life itself”' (Nagib 2016, 132). Panahi's overtly confrontational (non-)cinematic discourse is an eminent example of "accented cinema" (Naficy 2001). His artisanal and secret use of the camera in deterritorialized conditions and extreme limitations as regards profilmic space - house arrest, fake taxi interior - gives way for multilayered reflexivity, incorporating nonactorial presence, performative self-filming and theatricality as subversive gestures, with a special emphasis on the off-screen and remediated videoorality performed in front of, or directly addressed to the camera. The paper explores the ways in which the filmmaker's tactics become powerful gestures of "politicized immediacy" (Naficy 2001, 6) that call for the (inter)medial as an also indispensably political act (Schröter 2010). ${ }^{1}$
\end{abstract}

Keywords: Jafar Panahi’s films, non-cinema, reflexivity, intermediality, orality.

\section{The Camera in House Arrest. In the Context of Accented Cinema}

In an interview for Agence France-Presse in 2010, the year in which Jafar Panahi was arrested with the charge of propaganda against the Iranian government, he made the following statement: "when a filmmaker does not make films it is as if

1 This work was supported by a grant of the Ministry of National Education, CNCS - UEFISCDI Romania, project number PN-III-P4-ID-PCE-2016-0418. 
he is jailed. Even when he is freed from the small jail, he finds himself wandering in a larger jail. The main question is: Why should it be a crime to make a movie? A finished film, well, it can get banned but not the director" (Ryzik 2010). Jafar Panahi's films were born under the rule of the Islamic theocratic government that - contrary to the regime prior to the 1979 Iranian revolution, the Pahlavi era, characterized by the flourishing of the institution of cinema - has not favoured the art of cinema and has imposed serious restrictions on filmmaking. However, it is in this period that Iranian film has revived, has been relieved from under its subservience to the thematic, generic and stylistic palette of Western cinema and has evolved into an autonomous use of the medium, with several authorial contributions of filmmakers such as Abbas Kiarostami, Mohsen Makhmalbaf, Asghar Farhadi, Majid Majidi, to mention but the most notable ones, who have shaped the trend of the Iranian New Wave.

In 2010, after several years of conflict over his non-adherence to the official propaganda, his free treatment of social-political matters and the profoundly humanist perspective employed in his films, Jafar Panahi was sentenced to six years of prison and a 20-year ban on filmmaking. After a shortened imprisonment, his sentence was changed into house arrest; now he can freely move but is not allowed to leave the country and, above all, he is not permitted to make films. It is under these conditions that his recent films were born. While awaiting his sentence in house arrest, he made This Is Not a Film (2011), co-authored by Mojtaba Mirtahmasb, which was smuggled out of Iran on a flash drive hidden inside a cake, and presented at the 2011 Cannes Film Festival. His second illegal film, Closed Curtain, co-authored by Kambuzia Partovi, was made in 2013 and won the Silver Bear for Best Script at the Berlin Film Festival. His third work, Taxi Tehran, premiered at the 2015 Berlin Film Festival and won the Golden Bear for Best Film.

In close intratextual connection with earlier pieces of his oeuvre, pre-eminently The Mirror (Ayneh, 1997) and Offside (2006), his recent films reformulate the relationship between cinema and the "real," defying the limitations of filmmaking in astounding ways. The paper addresses the ways in which Jafar Panahi's works transgress the boundaries between documentary and fiction, the "real" and the mediated, cinema and non-cinema, pertaining to those instances of cinematic "impurity" in which "the medium disregards its own limits in order to politically interfere with the other arts and life itself" (Nagib 2016). As overtly expressed in the title of his 2011 film that reproduces the famous Magrittean phrase, "these are not films," but rather cries for help, manifestations of revolt, and, not least, games with the medium, responses of creativity in conditions of extreme limitation of creativity. 
Panahi's clandestine trilogy is an eminent example of "accented cinema." Hamid Naficy regards exilic and diasporic filmmaking as "accented cinema," where "the accent emanates not so much from the accented speech of the diegetic characters as from the displacement of the filmmakers and their artisanal production modes" (Naficy 2001, 4). Accented cinema, as he argues, "crosses many borders" (2001, 5), employing narrative strategies that transgress generic boundaries and subvert cinematic realism; it is characterized by creating in deterritorialized conditions and artisanal modes of creation; authorial styles; often by the presence of the author within the film in the interstice between fiction and autobiography; the subjectivity of the dislocated self inhabiting "sites of struggle" (Harlow quoted in Naficy 2001, 11); fragmentedness, openness and self-reflexivity. Internal exile represents a distinct case of accented cinema: "when they [accented filmmakers] speak from this site at home, they have an impact, even if, and often because, they are punished for it. In fact, interrogation, censorship, and jailing are all proof that they have been heard" (Naficy 2001, 11). Jafar Panahi's artisanal and secret use of the camera in deterritorialized conditions and under technological constraints - filmmaking under house arrest, filming in secret, disguised as a taxi driver - gives way for multilayered reflexivity, incorporating non-actorial presence, performative self-filming and media entanglement as subversive gestures infused with an implied political stance.

The films having "Mr Panahi" himself as the protagonist cross the generic boundaries of "home" movie, to be understood literally, in the sense that the film director allows the camera into his own home, transforming his own private spaces into the "house" of cinema. Throughout his cinematic career prior to the ban, Panahi used to pursue his profession as an urban flaneur, observing life in the streets of Tehran, 'at once a 'dreamer,' an 'artist,' a 'collector' and an 'archaeologist' who experientially reads the city and articulates his perceptions into filmic texts" (Niazi 2010, 3). Notwithstanding, he has recently turned into the protagonist of his own films, playing the - overt or camouflaged - role of the filmmaker. Thus, his surreptitious works can be regarded as ingenious film performances, centred on the subjectivity of the filmmaker at the boundary of the private and the public, pushed from behind the scenes into the foreground as a performer who utilizes his own personality and corporeality as a live medium in interaction with the cinematic apparatus within confined, claustrophobic spaces.

In This is Not a Film, a video diary documenting one day of the filmmaker awaiting his sentence, the camera directed at Panahi in his home emerges as a demonstrative act of protest against deterritorialization. Instead of being allowed 
to record the scenes of the planned film script, the cameraman-protagonist and co-author Mojtaba Mirtahmasb's DV camera, in alternation with Panahi's mobile phone camera, records the efforts of the frustrated film director to come up with some sort of replacement of his original plan. In lack of the possibility of shooting the film, Panahi proposes to enact himself a few scenes from his latest film script about a girl whose parents do not allow her to study at the university of art and close her in the house - the story itself being highly reminiscent of Panahi's own conditition. At a certain point, however, Panahi loses confidence: if a film can be enacted like this, what is the use of making the film itself? He says, he has to remove this cast similarly to Mina, the protagonist of The Mirror, and searches for singular moments in his earlier films, The Circle (2000) and Crimson Gold (2003), which testify to the fact that films are not entirely under the filmmaker's control, there are impulses in the amateurs' performance that emerge spontaneously in the process of shooting. [Fig. 1.] The film ends with the cameraman leaving and Panahi taking over his DV camera, shooting an impromptu dialogue in the elevator - an even more confined space - with the boy collecting the garbage in the building, a true amateur performance challenging the filmmaker's control. Finally, the camera follows the boy outside the block of flats and captures brief moments of celebrating Fireworks Wednesday, in the eve of the Persian New Year, taking place in the streets of Tehran.

In Closed Curtain, "a claustrophobically self-referential chamber piece" (Romney 2015), a fragmentary, solipsistic docufiction formulated as a perceivably desperate response to the situation of crisis, the interior of Panahi's own beach villa becomes the scene of a series of events which are later laid bare as being directed. A man hiding with his dog (dogs are considered unclean by the Islamic state) shaves his head to disguise his identity and covers the windows of the villa with black curtains [Fig. 2], then he is surprised by unexpected visitors, a girl, Melika, and his brother, Reza, persecuted by the authorities for consuming alcohol at a beach party. At a certain point the allegedly suicidal girl stops acting as before, starts pulling the curtains apart and with this gesture a metaleptic trangression of narrative levels takes place: the whole series of events, perceived so far as "real," are unveiled as scenes of a screenplay; the hiding man turns out to be Kambuzia Partovi, script writer and co-author of the ongoing film shot behind closed curtains. Panahi also turns up from behind the scenes, revealing the presence of the cinematic apparatus; on the uncovered walls posters of his former films, The Circle and The Mirror, become visible. Thus, Closed Curtain, also reminiscent of The Mirror, this time due to the twist in the narrative, evolves from an apparent 
documentation of the "real" to unveiling it as fiction, which induces a trompe l'oeil effect, acquires a Moebius ribbon-like character, denying/redoubling "reality" in a Magrittean manner. The allegorical film also incorporates floating, surreal scenes about the girl leaving the villa, walking into the sea and gradually disappearing in the water, then rewound and suggested that all has taken place in the filmmaker's dream. The suicidal girl turns thus into the alter-ego of the filmmaker, who associates escape and death with the situation of deprivation.

Panahi has apparently overcome the private crisis and found a loophole to unwrap his creative energies in his 2015 Taxi Tehran, an homage to Ten, Abbas Kiarostami's 2002 in-taxi drama. The scene of this ingenious docufiction/road movie is no longer the interior of an immobile location, as in his previous works, but that of the eponymous means of transport, also an enclosed space, which however, confers a mobile, dynamic setting and makes possible an urban flanèrie, letting Panahi and his camera back to the streets of Tehran. If the filmmaker is not allowed to move around and make films, then, with a brilliant reverse gesture, he will let the world in, allowing "reality" to perform itself in front of the camera, on the apparently improvised "stage" of the taxi interior. Equipped with dashboard cameras performing the surveillance of the passengers, the fake taxi driven by the filmmaker himself becomes the scene of lively episodes, and it remains playfully suspended throughout the film whether these have been staged, partly or fully, with employed actors, or we watch spontaneous moments of Panahi's taxi ride set up for shooting and it is just the everyday life in Tehran that provides this mottled mosaic. The puzzle is only reinforced by the absence of the cast in the closing credits. Matters of life and death, the entire Iranian reality unfold within the micro-universe of the taxi cab interior, with the passengers hopping in and out, bringing their stories and dramas as Kammerspiel type mini-capsules - just as the two elderly sisters bring their fish in a glass bowl that represents their own lives. The passengers are engaged in hilarious conversations with the taxi driver, some recognizing Mr Panahi at the wheel, some pointing at the camera, interacting with the camera (Nasrin Sotoudeh, suspended human rights lawyer, offers a rose for the spectators), some expressing their suspicion that he is just shooting a film - all these being inbuilt metaleptic gestures that give the salt and pepper of the film's comic ambiguity. [Fig. 3.] Starting with the first male passenger's argument with the female teacher whether thieves should be hanged (as a twist, he later introduces himself as being a pickpocket) and ending with two thieves robbing the taxi, the film is imbued with allusions to theft, which, complemented with a discourse unfolding on the relationship between filmmaking and reality - mainly 
in Panahi's conversation with his niece, Hana -, highlight the filmmaker's most important concern, namely remaining loyal to the "real," as opposed to the ruling ideology that marauds the essence of reality. The multiple references to cinema as well as the subtle passages created between autobiography and fiction, life and art, the spontaneous and the staged, turn the confined taxi interior into a reflexive playfield, an expanded space of reflection on socio-political realities. Thus, in these works, the confined profilmic spaces turn the films into allegories of the "real" and into parables of seclusion, and at the same time, they constantly point outwards and perform the miraculous transformation of closed spaces into open social-medial networks.

\section{Non-Cinema: From Media Technology to Media Politics}

In the first place, the issue of non-cinema is triggered by Jafar Panahi's own choice of film title. If "this is not a film," what are its qualities that go beyond the limits of the film medium? Perceivably, the statement is paradoxical to the same extent as the term "non-cinema" is.

In his seminal study entitled Non-Cinema: Digital, Ethics, Multitude, William Brown starts his argumentation by stating that "'non-cinema' is of course, paradoxically, cinematic," that "non-cinema is an intrinsic component, or quality, of cinema" $(2016,105)$. It is actually the digital image, he suggests, that necessitates repositioning what can be regarded as the "dark side," the non-cinematic "other" of cinema, a set of qualities that fall within rather than outside the scope of cinema. Through the analysis of diverse non-mainstream filmmaking practices overarching geographical bonds, the study looks at the sides of production/distribution and reception/perception, highlighting the technological as well as aesthetic aspects of what may be regarded as noncinema. The technological aspects may vary from the film director's expressed intention of making a non-film, ${ }^{2}$ through technological limitations due to low or no budget, material shot with a DV camera or other new media appliances, to forms of distribution that fall outside the institutional frameworks, while on an aesthetic level, non-cinema may embrace a whole range of tropes including low quality (grainy, shaky) or dark, hardly visible images, handheld camera work, amateur(ish) acting, otherwise not absent from mainstream cinema either but

2 Interestingly, as William Brown mentions in his study, the filmmaker from the Philippines often signs his works with the phrase "this is not a film by Khavn de la Cruz" (Brown 2016, 112) bearing much semblance to Jafar Panahi's eponymous label attached to his first film made under the ban. 
gaining an accentuated role in non-cinema. In his study, Brown also expounds on the paradox of the realism of the digital image, achieved through deliberate, non-cinematic flaws that simultaneously create and act against the impression of the "real." Hence "the simultaneously self-conscious and realistic treatment of the work" (Brown 2016, 122), which can also be addressed via the immediacy and hypermediacy of cinematic experience that constitute the double logic of remediation (Bolter and Grusin 2000). ${ }^{3}$

Beyond the technological and aesthetic features that may delineate the domain of non-cinema, the discourse of non-cinema also brings into discussion significant implications regarding the politics of the image. Informed by Enrique Dussel's philosophy of "non-being," encompassing qualities such as the peripheral, the barbarian and the wretched, as well as by François Laruelle's terms "nonphilosophy" and "non-photography," William Brown proposes rethinking "nonness" pertaining to cinema as a counter-discourse set against capitalist cinema and in favour of the liberation of cinema: "in some senses, non-cinema is equally not a rejection of cinema, in that these are still films. But it is a rejection of cinema as capitalist, as per Beller's formula, and it is a cinema of liberation, after Dussel" (Brown 2016, 127, with reference to Beller 2006). The author points at the discourse of non-cinema as "what demonstrates to us that what we define as cinema is a political as much as (if not more than) an ontological question" (Brown 2016, 110).

In her profound film-philosophical essay Non-Cinema, or The Location of Politics in Film, Lúcia Nagib traverses a distinct route in order to also point at the close interconnectedness between the negation of cinema and political engagement. ${ }^{4}$ She proposes to rethink the concept of "non-cinema" by historically tracing its origins among the major discourses pleading the "purity" vs "impurity" of cinema, paying special attention and tribute to André Bazin as the first to “intuit," as she says, the essence of non-cinema. Bazin's understanding of cinema as being the expression of, and profoundly interrelated with, the real, also implies the acquiescence of the real as what cinema can never ultimately reach. Thus, as Nagib infers from Bazin's foundational essay The Ontology of the Photographic

3 Such is the way in which lo-fi images direct perception, in-between transparency and opacity: "the low grade quality of the image - with the grain taking us away from a sense of transparency and towards a painterly sense of the image maker's intervention in what is being recorded" (Brown 2016, 122).

4 See also: Lúcia Nagib: From Non-Cinema to Total Cinema: A Reflection on Film beyond the Medium. Keynote speech at the international conference The Real and the Intermedial, organized by the Sapientia Hungarian University of Transylvania, Department of Film, Photography and Media, Cluj-Napoca, 23-24 October, 2015. https://www.youtube.com/watch?v=yExHA8xaJOQ Last accessed 15. 04. 2018. 
Image, "this early inkling of indexicality, which in semiotic parlance means the material link between sign and referent, was destined to become one of the most central concepts in film studies. But it was also a first intimation of non-cinema, insofar as it identifies cinema with reality only to demonstrate its insufficiency to fully signify it” $(2016,135)$. Based on an in-depth analysis of Bazin's realist aesthetic and the position it held in relation to the discourses of artistic modernism, ${ }^{5}$ the essay celebrates Bazin as the forerunner of thinkers who "resorted to negative dialectics to make the case for art in cinema" (Nagib 2016, 134), and discusses the French film theorist's concept of "impure cinema" as the nucleus of the major satellite terms of non-cinema. In this, she includes Adorno's "uncinematic," expounded on in his Negative Dialectics (1973) and proposed in defence of cinema as art; Lyotard's "acinema," set forth in his essay with the same title, Acinema, implying "what is fortuitous, dirty, confused, unsteady, unclear, poorly framed, overexposed” (Lyotard 1986, 349, quoted in Nagib 2016, 136) and, together with that, the enjoyment of cinema as art, propagating an anti-utilitarian approach; and finally, Alain Badiou's "impure cinema," elucidated in his Handbook of Inaesthetics (2005), echoing Bazin's term and idea of incorporating the other arts and, at the same time, identified as the location of the real. Thus, as the essay suggests, non-cinema should be conceived as the "impure" quality of cinema that distances cinema from itself and approaches it to the real and the other arts, embracing the ways in which "the medium disregards its own limits in order to politically interfere with the other arts and life itself" (Nagib 2016, 132).

The two essays outlined above, foundational as regards the positioning of non-cinema on the map of film theory, albeit applying distinct methodologies in discussing the subject, converge, first of all, in the recognition of non-cinema as a key issue as regards the politics of the medium.

Non-cinema is not an external "other," but is inherent in, constitutive of, the concept of cinema. As Brown suggests, the option for non-cinema is the result of an ethical decision: "so to choose to look at cinema in this way, democratically to see both cinema in non-cinema and non-cinema in cinema, becomes an ethical choice" $(2016,125)$. Non-cinema allows for cinema to go beyond its limits, in the sense of being itself "enworlded, entangled" in the "real" (Brown 2016, 125)

5 Philip Rosen's essay From Impurity to Historicity, analysing Bazin's concept of - the often mistranslated - "impure cinema" is highly revelatory as concerns the position of Bazin's view in the context, and even resistant to the context of modernism: "Bazin's notion of impure cinema not only opposes the historical avant-garde in cinema, but also a basic premise of much classical film theory. In so doing, it may superficially seem to go against the grain of the modern/ modernist project, of defining the uniquely new in the cinematic” (Rosen 2014, 8). 
and being "in permanent communion with what it was not [in Bazin's view]: the other arts and real life" (Nagib 2016, 133-134). As William Brown argues, "noncinema asks for a politicized, or an ethical, engagement with digital cinema, such that its democratic ontology is not only understood, but perhaps also honoured politically" (Brown 2016, 107-108), idea that he extensively dwells on in his fresh book on non-cinema, which formulates the thesis that non-cinema challenges "the limits of cinema and, by extension, the limits of what is constituted as real in our world of cinema-capital. Non-cinema is for this reason a point where aesthetics meets politics" (Brown 2018, 2). The examples brought up to support the argumentation in Nagib's essay are meant to underpin the affirmation that the act of transgressing the borders of medium specificity and stepping into the realm of the life and the other arts is emphatically a political act in the sense of "negating cinema in order to let reality speak for itself" (Nagib 2016, 147).

The second point of convergence can be identified in the recognition of subtle forms of in-betweenness that non-cinema instates, arising from the ambiguity of the perceived moving image situated, on the one hand, in-between distinct technologies of mediation, transparency and opacity, fiction and documentary, as Brown argues, and, on the other hand, the real and the intermedial, as Nagib elaborates. The status of in-betweenness of non-cinema ensues from its dynamics of displacement and transgression, from its marginal position, raw matter and blurred contours, which become all the more significant in the recognition of the non-cinematic gesture as a political act that distances itself from the cinema and, synchronously, folds back on the "real."

\section{Jafar Panahi's Non-Cinema: Passageways between the "Real" and the (Inter)Medial}

Jafar Panahi's filmmaking practice may serve as an illustrative example of noncinema, a political act and, at the same time, a multilayered, proliferating site of in-betweenness. His recent clandestine cinema stands on the grounds of his overt self-exclusion from the realm of cinema, as declared in the title of This is Not a Film, ensuing from his conflict with the Iranian authorities, the financial and technological limitations, as well as the concomitant aesthetic decisions, including self-performance in front of the camera (This Is Not a Film), low quality images due to secret shooting (Closed Curtain), and amateur(ish) acting (Taxi Tehran). Jafar Panahi's non-cinema, performed as a gesture of defiance, has turned into a powerful reinscription into, and an ingenious extension of the 
discourse of cinema, in a way that his non-cinema only adds to the rethinking of the aesthetic of contemporary cinema and its relation to the "real."

Panahi's This is Not a Film pre-eminently figures among the examples analysed by William Brown and Lúcia Nagib as one standing for a "raw" film aesthetic, made partially with a mobile phone, and as a confrontational and self-reflexive work created on behalf of the politics of the "real." As Panahi's earlier, similarly selfreflexive (non-)film, or counter-documentary, ${ }^{6}$ The Mirror - embedded in This is Not a Film and also discussed in Nagib's essay as "another relentless exercise in selfnegation” $(2016,131)$ - suggests, Panahi has actually always pursued non-cinema. It can be said that with the ban his latent and implied non-cinematic practice has become overt and declared, and there are only differences in degree between his earlier and more recent films in this respect. Panahi's recent cinematic counterdiscourse designates a border zone in which the relationship between the medial and the political is explored in a way that they incessantly overwrite each other.

The title This is Not a Film evokes the Foucault who extensively wrote about social exclusion and who wrote about Magritte's work: "Ceci n'est pas une pipe exemplifies the penetration of discourse into the form of things; it reveals discourse's ambiguous power to deny and to redouble" (Foucault 1983, 37). Analogously, Panahi's non-films can be regarded as ways in which discourse penetrates into the form of things, denying and redoubling the representational layers and attesting the performative power of the medium: the way the rejection of the situation that hinders the filmmaker in pursuing his profession turns into an affirmative gesture, the non-film becoming the film itself, this is how the film elevates to a state where it can perform its own politicized mediality. The physical seclusion of the filmmaker and the ban on filmmaking relocate film at the boundary of cinema, a liminal place where the exposed mediality of film becomes a political gesture of resistance. Evidently, there is a positive message in this gesture, implying that no limitation imposed upon cinema can prevent the devoted filmmaker from creation. Spatial, physical alienation is impossible since beyond political matters, cinema is where the human being is, indeed an

6 According to Joanne Richardson, counter-documentary films "employ the conventions of documentary but simultaneously negate their fulfillment. Sound-image discontinuity, image distortion, interruption of natural time sequences, use of alternative speeds, faked oraltestimony by actors, and the misappropriation of newsreel footage in incongruous contexts have all been used to create counter-documentary effects" (Richardson 2000). In The Mirror, the aleatory moment of the girl's stepping out of her role, laying bare the cinematic apparatus, the asynchronity of the image frame and the sound frame arising from the position of the microphone that remained attached to the girl after she had left the crew, all count as counterdocumentary effects. 
extension and prosthesis of man in the McLuhanian sense, resulting in a sort of counter-cinema, a privileged site of in-betweenness, between art and life itself, between the medial and the political, testifying to the way in which "cinema's dissolution into other art forms and life itself results in transformative politics" (Nagib 2016, 134). Thus, limitation becomes a site of experimentation, pushing the boundaries of cinema where anti-cinema experiments become gestures of "politicized immediacy" (Naficy 2001, 6) that call for the (inter)medial as an also indispensably political act (Schröter 2010).

The intermediary position of Panahi's non-cinema, in-between the medial and the political, entails that his films qualify through an emphatic shift in both directions. On the one hand, they fall within the scope of political cinema - a discourse opposed to mainstream cinema and thus figuring in William Brown's survey of the satellite terms of non-cinema - as they touch upon issues that go beyond the particular case of the banned filmmaker and lead into the public sphere, the private subject becoming a politicized subject. On the other hand, their media-orientedness and heightened reflexivity locate them in the realm of meta-cinema, laying bare the cinematic apparatus and bestowing memorable film-within-the-film moments upon film history. Panahi's works also stand for significant media events, triggering reactions in the social media internationally. In her survey of Iranian Cinema and Social Media, Michelle Langford regards Jafar Panahi's 2011 film as a social media event, "not so much a film, but the content of newer media, an intermedial vehicle for spreading a crucial message" (2015, 266). As the author suggests, This is Not a Film becomes the content of newer media, similarly to the way in which it contains a plethora of media references, from Panahi's earlier films and object traces of his cinephilia - an old camera, DVDs of films, photos of old film stars - to his own diverse media use, including the mobile phone, the laptop, the DV camera, the TV screen. In Langford's use of the term, intermediality is applied with reference to the multimedia environment surrounding the film director in his home, a space "into, through, and ultimately out of which a range of old and new mediatized images, ideas and products flow" (2015, 265). The way This is Not a Film incorporates, and resonates with images of earlier films, The Mirror, The Circle and Crimson Gold respectively, turns into a subtle intratextual metafilmic discourse; what is more, "if The Mirror is already an example of meta-cinema, then This is Not a Film becomes perhaps a form of meta-meta-cinema" (Langford 2015, 266).

Throughout his cinematic activity, Jafar Panahi has always remained under the spell of reflexivity. What may, prior to the ban, have been a reflexive game with 
the medium, at the same time "solidly anchored on a real that clashes against and ruins the possibility of a conventional film" (Nagib 2016, 142) - as testified by the story of Mina, the little protagonist of The Mirror, who in an unexpected moment removes her cast, leaves her role and the entire staff behind only to get lost, but discretely followed by the camera, in the labyrinth of Tehran's unconcerned adult society - has deepened in the recent years in the direction of an even more emphatic reflexivity, employed in a site of crisis and developing into the dominant strategy of Panahi's non-cinema. With him, the "real" becomes visible together with the camera that records it; the camera also becomes part of the "real" to the same extent as the "real" is evinced via a pervasive reflection on the cinematic medium. Nevertheless, with Panahi, the "real" is not a mere matter of self-sufficient reflection, distanced by pushing the medium and mediality into the foreground, by the discourse of representational criticism in the Derridean sense of infinite regress; on the contrary, the Real, capitalized and without quotation marks, so to say, is there indeed, palpably, painfully, drastically limiting - but from a shifted angle, also extending - the scope of cinema. In what follows, I will examine, in turn, the applied tactics of what I have identified as the major strategy of Panahi's clandestine (non-)cinema, contending that these tactics never remain within the confines of the "purity" of the medium as an end in itself but forcefully resort to "impurities" of cinema, as proposed by Lúcia Nagib, on Bazinian grounds, in the sense of reaching out towards "the other arts and life itself" (Nagib 2016, 132), filling the gap of medium insufficiency and as such regarded as "a useful tool, one which allows us to identify political materials capable of advancing film theory in new and exciting directions" (Nagib 2014, 29).

One of the idiosyncrasies of Panahi's art, at the same time, the major tactic of non-cinema extended in the direction of meta-cinema, is the presence of the camera, laying bare the cinematic apparatus. It is perhaps not an exaggeration to affirm that the camera advances into the role of the protagonist in Panahi's three recent films, performing surrogate roles in the absence of a free utilization. In This Is Not a Film, at the end of the day, in lack of any other filmic material to record, two recording appliances, Mirtahmasb's DV camera and Panahi's mobile phone, are pointed at each other, bitterly mocking at media-reflexive gestures of avant-garde art; here, however, it is the framing reality that turns this moment of apparently forlorn reflexivity into an act of defiance. "It's important that the cameras are on," these are the words with which Mirtahmasb leaves Panahi's home, emphasizing the importance of documentation, of making the "real" visible through its mediation. In their resulting video diary the cinematic 
dispositif, made visible, appears as a tool set against the dispositif or apparatus of power (Foucault 1980; Agamben 2009). In other words, the technology of the medium is set against the technology of power, finding thus a niche in the solid construction of prohibition through the demonstrative act of using the camera, whereby the image performs its own "politicized immediacy" (Naficy 2001, 6). In Closed Curtain, recording evolves from invisibility, from observing the events taking place in the seaside villa to being unveiled, in a metaleptic twist, as an accomplice in recording scenes of a pre-planned film script, revealing the real identity of the emerging figures as the script writer Kambuzia Partovi and the actress Maryam Moqadam playing Melika's part. Here, laying bare the situation of shooting, making visible the filmmaker in his own villa and the posters of his own films previously hidden behind veils confronts the discourse of the "real" with the discourse of meta-cinema, showing the two in a particularly close entanglement. In Taxi Tehran the presence of dash cams is complemented with the passengers' own recording media. Such are the injured man's mobile phone on which he attempts to record his last will, becoming an accomplished caricature of media-freak society, and the camera with which Hana, Panahi's little niece shoots her own film, negotiating with the boy caught in the act of stealing the money from newlyweds to perform again and restore his actions otherwise he spoils her film. She tries to make a film that complies with the teacher's instructions favouring the discourse of official film propaganda, prescribing the norms of filmmaking and tampering reality. The dialogue between Panahi and Hana clearly marks the borderline between Iranian mainstream ideology and Panahi's oppositional non-cinema. [Fig. 4.]

The presence of the camera entails, as another tactic within the strategy of reflexivity, performance for the camera. Filming the filmmaker, the protagonists' self-filming, filming the camera or "filming back" are moments of heightened reflexivity, exploring to the full the possibilities of the self-conscious mode of filmmaking. At the same time, it is important to emphasize that these self-reflexive moments are, ultimately, attempts at enacting the "real" in front of the camera, transmitting an image about the "here and now," having effect thus in accordance with the double logic of immediacy and hypermediacy. On-camera performance in (mimicked) real time, implying breaking the fourth wall, a rupture in the sense of a self-sensing and self-displaying awareness, approximates the film medium to today's new media practice, to the genre of the vlog, with all the ensuing tension arising from the intermedial junction between film and new media. Panahi conveys an image of Iran where people are avid media users and media consumers, keen 
on speaking about film and media when caught in interaction with some sort of media appliance, and eager to join games of mediation at any time.

Self-enactment ${ }^{7}$ interspersed with direct camera address is perhaps the most spectacular in This is Not a Film. In order to provide some sort of surrogate of the film's setting, Panahi traces out the area of the girl's room with an adhesive tape on the Persian rug from his living room. [Fig. 5.] The carpet, in itself a mise en abyme - that of the world -, is empowered to "imagine" the film and morphs into a mise en abyme of cinematic space. In its two-dimensional materiality, it becomes an allegorical signifier of the film screen, "where idea meets matter" (Marks 2013, 16). It models another dimension of the medium that breaks down the "round" cinematic experience into a "flat," atavistic and syncretic mode of expression, that is, the molar into the molecular along Laura U. Mark's (2013) phenomenology of "thinking like a carpet." Panahi's enactment turns into a metacinematic process, a forceful tactic of non-cinema pointing at the limits of representation, which at the same time is even capable of deluding the ban. As Panahi says in the film, "20 years ban from film-making, 20 years ban from writing screenplays, 20 years ban from leaving the country, 20 years ban from having interviews. Acting and reading screenplays were not mentioned." Reading the film script aloud, adding verbal comments and setting the scenes in space, all this carried out by the film director alone, form part of a process of transmediation that turns the screenplay into a mental film-within-the-film.

The one-person enactment of the unmade film involves corporeal presence and material immediacy, while what is enacted, the film itself, is absent, is praesentia in absentia. The spectator is invited to imagine what the filmmaker imagines, a film that is not there, unmade, unseen, come undone, doomed to failure but still coming to life beyond the grasp of the medium: a non-existent film, noncinema indeed, which reaches out into the invisible and thus performs what all art aspires to. The mental images transform external representation into internal representation; in a media archaeological sense, "the ambivalence of endogene images and exogene images, which interact on many different levels, is inherent in the image practice of humanity" (Belting 2005, 304). ${ }^{8}$ The transmediated,

7 Enactment, in its diverse forms of manifestation and with its multiple, often meta-cinematic connotations, is frequently present not only in Jafar Panahi's oeuvre, e.g. in his 2006 Offside, in which the girls who are not allowed, on a gender basis, to enter the stadium and watch the football match enact it "offside," but also at other Iranian filmmakers, e.g. in Mohsen Makhmalbaf's Hello Cinema (Salaam Cinema, 1995), a movie about casting, in which the applicants have to perform themselves in front of the camera.

8 What is more, as Belting points out, this interaction pertains to the politics of images: "the interaction of mental images and physical images is a field largely unexplored, one that 
enacted mental film, as non-image, slips out from under the authoritative regulations referring to the medium, and creates a space of freedom. Hence the performative power of enactment as embodied, ethical response, the emanating force of non-representation, gaining its contours as an immaterial artwork that opens up a shared space of solidarity between the filmmaker and the spectator. Enactment, with its implied performative power, also carries a critical potential by reflecting a situation of deprivation and becoming a form of resistance, folding the medial upon the political.

Performance for the camera entails, in Panahi's discussed films, an accented role of orality. Together with the narrowing of the scope of filmmaking, which implies confined spaces, limited action, often deliberately performed for the camera, and tendentiously reserved camera movement, the utilization of the verbal channel becomes more pronounced, to such an extent that its foregrounded mediality permeates the cinematic experience. With Panahi, accented orality gets shape in a temporal in-betweenness, perceptibly arising from deep down the Persian traditions and meeting the "third orality"9 of the digital age. It may result from the video diary format, as in This Is Not a Film, centred on the interaction between the performing body and the recording apparatus, with the implied theatricality of enactment, where speech takes over the leading role and is intended to compensate for, reflect on, process the constrained condition and supplant inertia with action, stasis with motion, that is, to reanimate lifelessness and gain back the spirit of the cinematic. The verbal channel also makes possible an ingenious extension of the profilmic by using the off-screen voice through mobile phone conversations: the voices of family members, the lawyer, colleagues and friends populate the film's soundscape and endow it with such dynamism that would otherwise be absent from the spectacle. In Closed Curtain, the main area of action is, again, the predominance of the verbal channel, manifested through the female character's allusive, theatrical way of speaking and through the male protagonist's oral performance for his mobile phone with the aim of documenting and reconstructing the events. A particular layer of the Persian theatrical tradition is also subtly interwoven into this work: its Persian title, Pardeh, alludes to pardeh khani (literally meaning "reading off the curtain"), one

concerns the politics of images no less than what the French call the imaginaire of a given society" $(2005,304)$.

9 "Today, we have entered another stage of orality. Now orality relies on rewriting, downloading, recording, transmission and networking. Oral voices are heard everywhere, but given authority through a number of presentation and storing media, from the blog to the pod-cast. This is the ‘third orality.'” (Rasmussen 2014, 27-28.) 
tradition in the Persian theatre - intermedial in itself - referring to the dramatized narration of historical events or religious-allegorical scenes, involving acting and singing, which takes place in front of a painted curtain. In Panahi's film, the curtain is black, suggesting a void of representation, and the protagonist's and his dog's staring at it becomes a form of passive resistance. [Fig. 2.]

Mediated orality becomes perhaps the most conspicuous in Taxi Tehran, which explores to the full the possibilities of verbal action under the limited circumstances of action within the taxi cab. The passengers, especially Hana, the little girl, are characterized by exceptional verbosity, complemented with the sensory experience provided by the Farsi/Persian language, and their corporeality and gestures are framed in performative interaction with media technology. They are eager to express and share their opinion, shaping a micro-society that speaks out social and political matters, thus the taxi interior becomes a forum to exchange views and opinions, and the medium of film frames and conveys this direct channel of verbal expression. Human voice becomes a discussion topic between Panahi and Nasrin Sotoudeh. Panahi says: "I've heard a voice before seeing you. The voice of a person I heard when I was imprisoned." Sotoudeh gives another dimension to the importance of voice by saying that "It often happens to my clients. They focus on voices. That's the effect of being blindfolded." This also explains the importance of voice at an abstracted level, in the larger jail that is the coutry, or even more, the entire world itself. As she concludes, eerily echoing Panahi's thoughts expressed in his 2010 interview for Agence FrancePresse, quoted at the beginning of the paper: "they make your life a prison. You go out, but the outside world is nothing but an even larger prison. They make your best friends your worst enemies. You will have to flee the country, or you leave praying for a safe return. So there is nothing else to do: Nothing to do!" It is in this socio-political context that the significance of voice, distributed on the film reel, emerges as a powerful act and tactic of non-cinema.

\section{Conclusions. Shifting Forms of In-Betweenness}

Panahi's non-cinema arises from the fundamentally non-cinematic condition of the ban on filmmaking, and develops ways in which this very condition is thematized, incorporated and, ultimately, defied through the particular impurities characteristic of his works: playing off the forms of documentary and fiction against each other; creating multiple passageways between the "real" and the mediated; an accentuated self-reflexivity achieved through metaleptic transgressions, through 
laying bare the cinematic dispositif as well as through a strong metafilmic discourse developed in the most varied manners; mise-en-scènes in-between the natural and the artificial, the spontaneous and the premeditated, the professional and the amateurish, transparency and (haptic) opacity, immediacy and hypermediacy, demarcating a site "between-the-images." This latter term was conceived by Raymond Bellour as a space of multiple passageways between the "real" and the reality of the image: "this is how images now come to us: within the space where we must decide which of them are real images. That is to say a reality of the world, as virtual and abstract as it may be, reality of an image-as-possible-world" (2012, 17). Panahi's works reserve themselves the right of medially overwriting reality, of always setting up a camera somewhere, becoming therapeutic means through the belief in the power of, indulgence in the reality of the camera. However, he places the camera in positions in which the "real" overwrites any attempt of its medial harnessing. The "real" is not just "out there," it breaks in, literally: in Closed Curtain, while making the film in secret, a break-in takes place (or is pretended to take place, in the spirit of the film's fruitful ambiguity), altering the direction of further shooting. Melika, the female character tells the script writer/protagonist: "you can't steal reality," challenging the realist claim of the film. Thus, Closed Curtain fails to access the "real" via a film script but manages to touch upon it by laying bare the failure in a metaleptic twist. Thus the crisis of representation results in the fruitful moment of reflection. Taxi Tehran ends with the taxi left on its own and being invaded and robbed by two thieves recorded by the surveillance camera. It suggests that life proves to be larger than what the filmmaker can hold under control, but this is the way in which it truly gets into the focus of the camera, in line with Panahi's realist aesthetic, maintaining a subtle, shifting inbetweenness in this respect throughout his works.

As a conclusion, the three films made in illegality ${ }^{10}$ seem to find their way ever closer to the "real," revealing "the entangled, becoming reality that allows cinema to exist" (Brown 2018, 4), with an implied awareness of the insufficiency of the medium to ultimately reach it, thus maintaining their accented, overt, playful, challenging, stimulating, politicized mediality in conformity with the entire Panahian oeuvre.

10 Complemented, at the deadline of the present article, with the fourth, most recent Three Faces (Se rokh, 2018), the theme of which resonates with the film script read aloud in This Is Not a Film. In Panahi's new film - winner of the Best Screenplay Award at the 2018 Cannes Film Festival -, Behnaz Jafari, an Iranian actress, and Jafar Panahi, acting themselves, are in search of a girl, Marziyeh Rezaei, after receiving her video message in which she cries for help to escape from her patriarchal environment and to attend the drama conservatory to become an actress. 


\section{References}

Agamben, Giorgio. 2009. What Is an Apparatus? and Other Essays. Stanford, CA: Stanford University Press.

Bazin, André. 1967. My Total Cinema. In What is Cinema?, 16-21. Berkeley, Los Angeles and London: University of California Press.

Beller, Jonathan. 2006. The Cinematic Mode of Production: Attention Economy and the Society of the Spectacle. Lebanon, N. H.: University Press of New England.

Bellour, Raymond. 2012. Between-the-Images. Zürich, Dijon: JRP Ringier \& Les Presses du Réel.

Belting, Hans. 2005. Image, Medium, Body: A New Approach to Iconology. Critical Inquiry vol. 31, no. 2 (Winter): 302-319.

Bolter, Jay David and Richard Grusin. 2000. Remediation. Understanding New Media, Cambridge, MA - London: The MIT Press.

Brown, William. 2016. Non-Cinema: Digital, Ethics, Multitude. Film Philosophy vol. 20, no. 1: 104-130.

Brown, William. 2018. Non-Cinema: Global Digital Filmmaking and the Multitude. New York, London, Oxford, New Delhi and Sydney: Bloomsbury Academic.

Foucault, Michel. 1980. Power/Knowledge: Selected Interviews and Other Writings, 1972-1977. New York: Pantheon Books.

Foucault, Michel. 1983. This is Not a Pipe. Berkeley, Los Angeles and London: University of California Press.

Langford, Michelle. 2015. Iranian Cinema and Social Media. In Social Media in Iran: Politics and Society after 2009, eds. David M. Faris and Babak Rahimi, 251-269. New York: Suny Press.

Marks, Laura U. 2013. Thinking Like a Carpet: Embodied Perception and Individuation in Algorithmic Media. Acta Universitatis Sapientiae, Film and Media Studies vol. 7: 7-20.

Naficy, Hamid. 2001. An Accented Cinema. Exilic and Diasporic Filmmaking. Princeton and Oxford: Princeton University Press.

Nagib, Lúcia. 2014. The Politics of Impurity. In Impure Cinema. Intermedial and Intercultural Approaches to Film, eds. Lúcia Nagib and Anne Jerslev, 21-39. London and New York: I. B. Tauris.

Nagib, Lúcia. 2016. Non-Cinema, or the Location of Politics in Film. FilmPhilosophy vol. 20, no. 1: 131-148. 
Niazi, Sarah. 2010. Urban Imaginations and the Cinema of Jafar Panahi. Wide Screen vol. 1, no. 2: 1-14. http://widescreenjournal.org. Last accessed 05. 06. 2018.

Rasmussen, Terje. 2014. Personal Media and Everyday Life: A Networked Lifeworld. Houndmills: Palgrave Macmillan.

Richardson, Joanne. 2000. Est-Ethics of Counter-Documentary. ARTMargins Online June 16. http://www.artmargins.com/index.php/featured-articles-sp829273831/421-est-ethics-of-counter-documentary. Last accessed 14. 04. 2018. Romney, Jonathan. 2015. Taxi Tehran Review - Jafar Panahi’s Joy Ride. The Guardian November 1. https://www.theguardian.com/film/2015/nov/01/taxitehran-review-admirable-jafar-panahi-takes-to-the-streets. Last accessed 23. 06. 2018.

Ryzik, Melena. 2010. Strange Bedfellows: Koch and London Critics Heap Praise on 'King's Speech. December 21. https://carpetbagger.blogs.nytimes. com/2010/12/21/strange-bedfellows-koch-and-london-critics-heap-praise-onkings-speech/. Last accessed 12. 06. 2018.

Rosen, Philip. 2014. From Impurity to Historicity. In Impure Cinema. Intermedial and Intercultural Approaches to Film, eds. Lúcia Nagib and Anne Jerslev, 3-20. London and New York: I. B. Tauris.

Schröter, Jens. 2010. The Politics of Intermediality. Acta Universitatis Sapientiae, Film and Media Studies 2: 107-124. 


\section{List of Figures}

Figure 1. Panahi reflecting on a moment of undirected amateur performance in The Circle (2000). This Is Not a Film (In film nist, Jafar Panahi and Mojtaba Mirtahmasb, 2011).

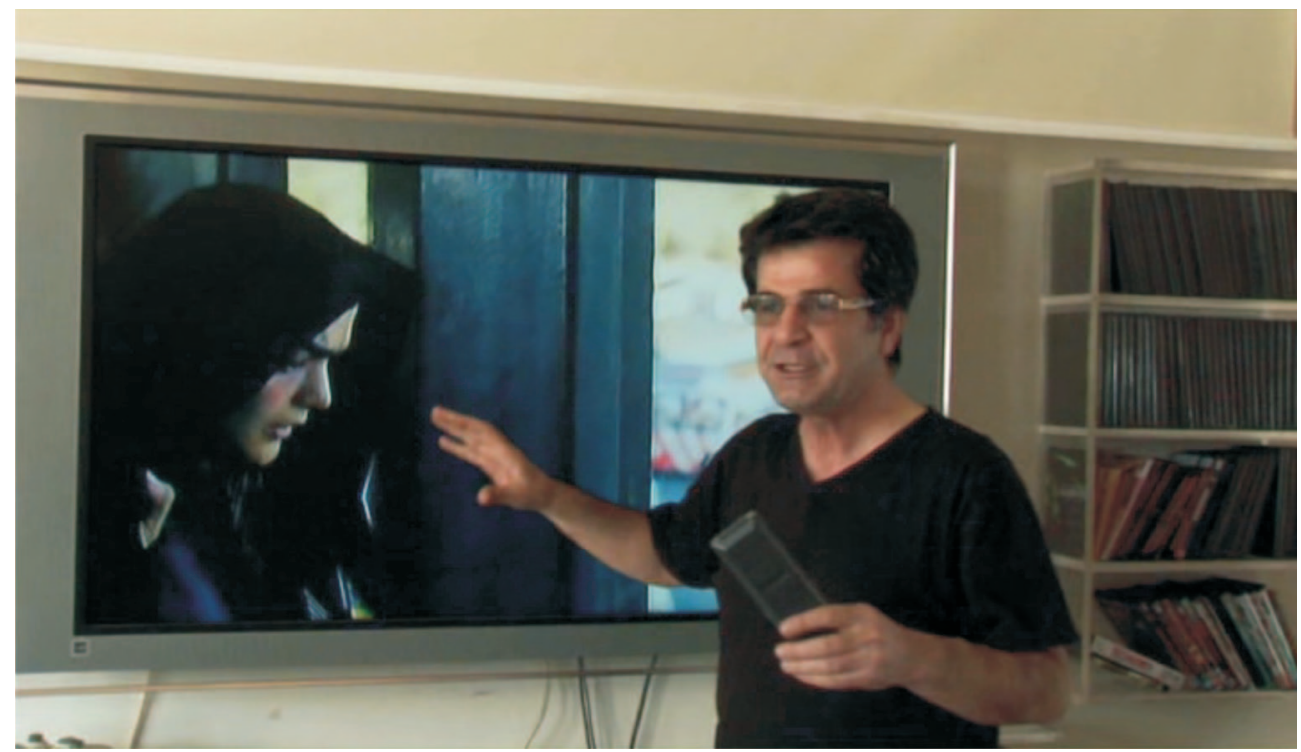

Figure 2. Closed Curtain (Pardeh, Jafar Panahi and Kambuzia Partovi, 2013), the protagonist and his dog staring at the black curtain.

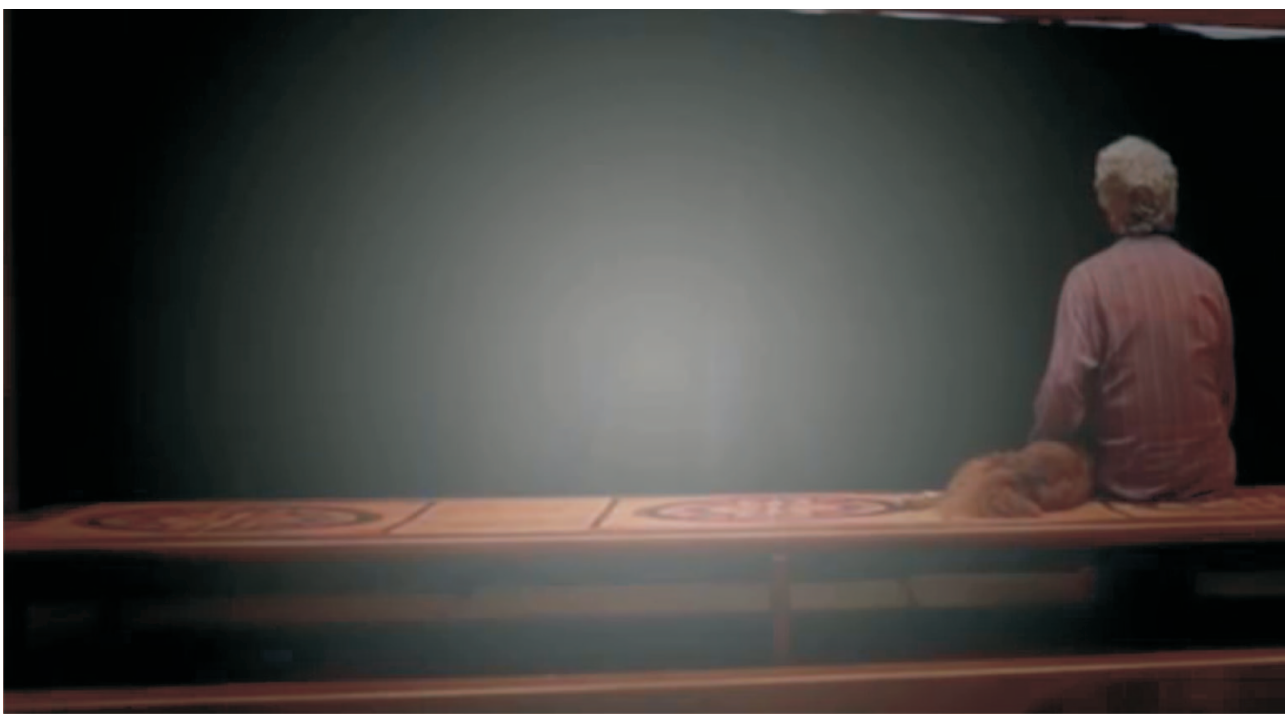


Figures 3-4. Nasrin Sotoudeh pointing at the dashboard camera. Hana shooting her own film, and negotiating with "reality" in Taxi Tehran (Jafar Panahi, 2015).
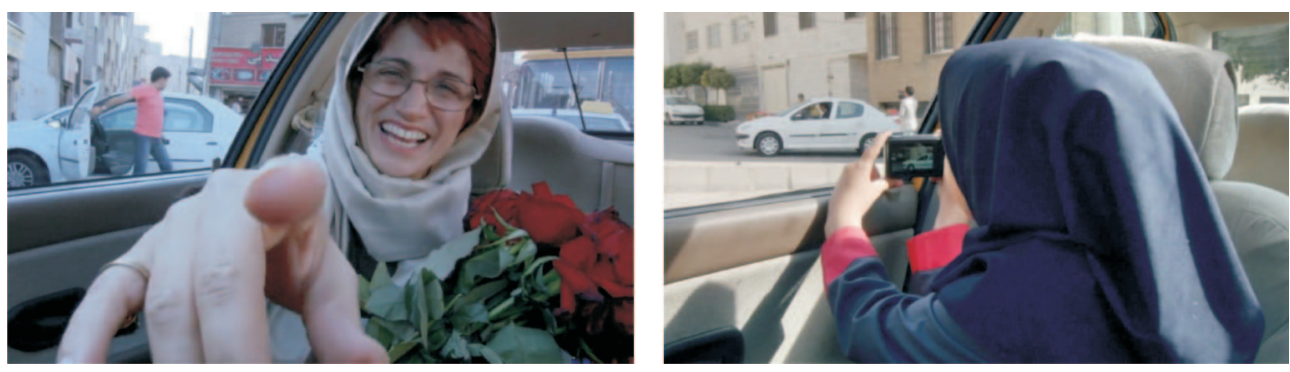

Figure 5. Panahi's enactment of his unmade film in This Is Not a Film (In film nist, Jafar Panahi and Mojtaba Mirtahmasb, 2011).

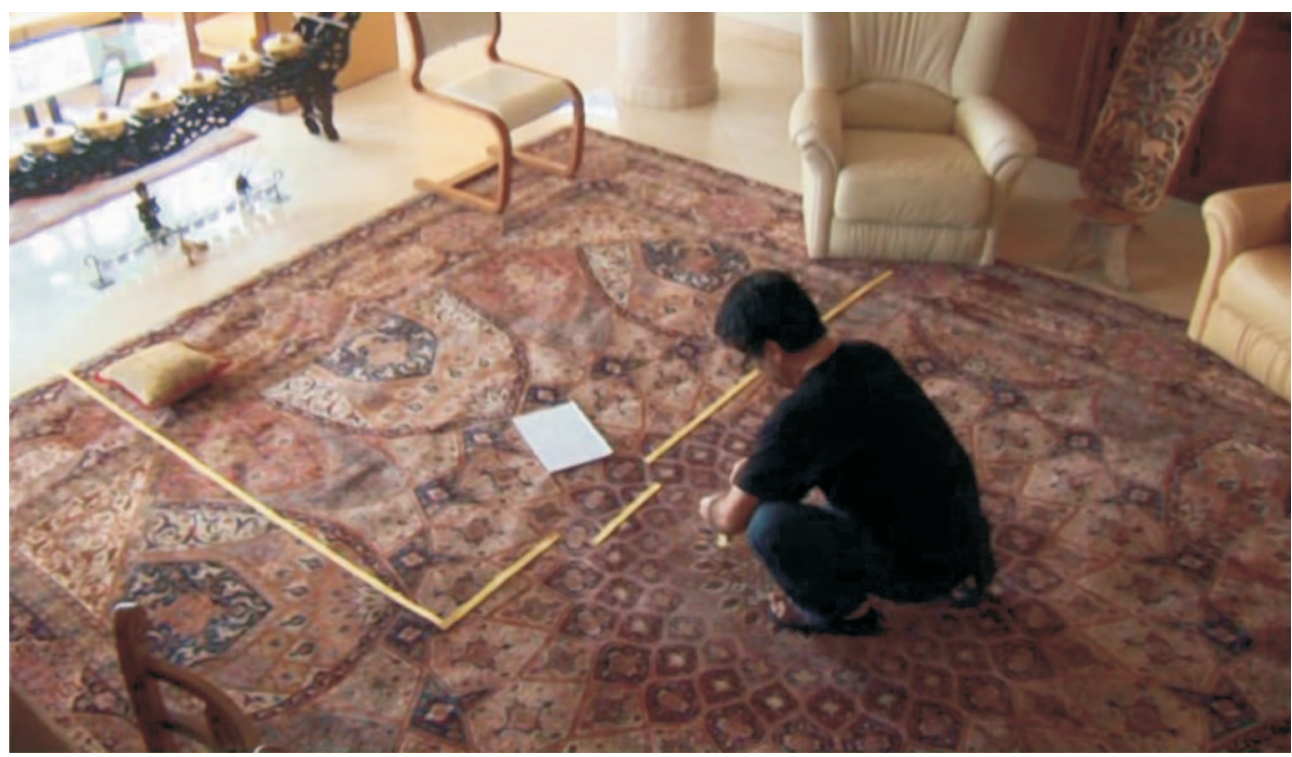

